\title{
Les médecins personnels
}

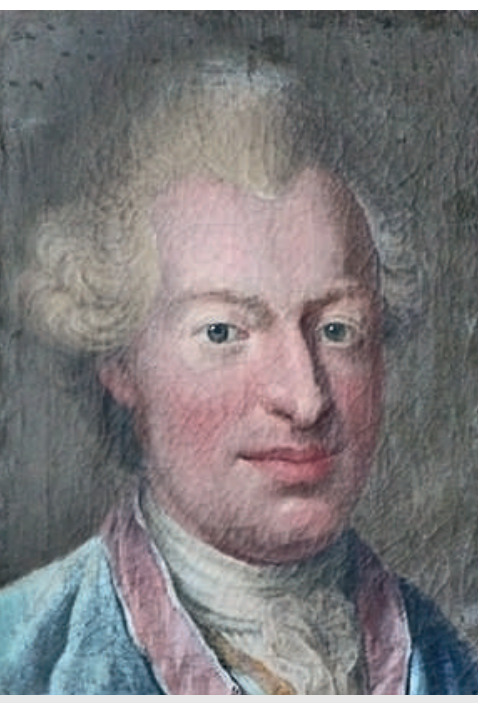

A fini sur l'échafaud: Johann Friedrich Struensee, médecin personnel du roi du Danemark Christian VII.
1 Enquist PO. Le médecin personnel du roi. Arles: Actes du sud; 2002.

2 Bashir A. The Insider. London: Brown Book Group; 2005.

3 Zhisui L. The Private Life of Chairman Mao. London: Random House; 1996.
Les médecins personnels au service des puissants ont des connaissances d'initié auxquelles nous n'avons aucun accès. Plus que par leur art, nous sommes donc fascinés par leur position sociale. Ils ont intéressé les historiens, certains sont devenus des héros de romans et de films, plusieurs ont même écrit leur biographie. A l'ombre de leurs maîtres, ils sont eux-mêmes devenus puissants ou ont payé leur position de leur vie. Au cœur du pouvoir, le métier de médecin personnel ressemble à un numéro de funambulisme. En effet, le risque augmente à mesure qu'on s'élève dans la hiérarchie et plus dure sera la chute - la roche Tarpéienne est près du Capitole. Si nous sommes très bien renseignés sur certains d'entre eux, d'autres ne sont jamais sortis de l'anonymat, fondus dans la foule des courtisans, trésoriers, garde du corps, cuisiniers et chauffeurs.

Un exemple unique dans l'histoire est celui de Johann Friedrich Struensee [1], qui, de médecin des pauvres qu'il était à Altona, s'est hissé jusqu'au poste de ministre secret du Cabinet à la cour du roi de Norvège-Danemark. Après avoir combattu le servage par des ordonnances, supprimé la torture par décrets et mis enceinte la reine, il a fini victime d'une intrigue en 1772.

Le XXe siècle a été le théâtre de drames qui surpassent en bizarrerie, en grotesque et en cruauté toutes les tragédies qui les ont précédés. Dans son film «Le dernier roi d'Ecosse», Kevin Macdonald a donné en 2006 une description saisissante du destin d'un médecin missionnaire en Ouganda, dont Idi Amine Dada avait fait son médecin personnel. Quiconque survit à la chute d'un tyran dont il était le médecin peut s'estimer heureux. Theo Morell, urologue, fabricant de poudre contre les poux et médecin personnel d'Hitler de 1936 à 1945, s'est échappé de Berlin in extremis. Il est mort discrètement des suites d'une longue maladie. Son confrère Miron Wowsi, médecin personnel de Staline, a été sauvé par son attaque cérébrale de la terreur exercée contre les prétendus auteurs du «complot des médecins» en 1953. De nombreux médecins de renom ont été victimes de cette campagne dirigée surtout contre les médecins juifs. Il arrive que ceux qui règnent par la violence finissent par tomber dans leur propre piège. Tous les puissants ne reçoivent pas le meilleur traitement médical possible. Staline inspirait une telle peur qu'il s'est retrouvé gisant sur le sol pendant des heures sans que personne n'ose s'en approcher. Un temps précieux a ainsi été perdu avant son traitement - au demeurant bien insuffisant - par hirudothérapie. Encore plus longue a été l'agonie du Généralissime Franco, que son médecin personnel et une équipe de spécialistes se sont acharnés à maintenir en vie pendant des semaines par crainte des conséquences en dépit d'un Parkinson avancé, d'une insuffisance cardiaque et d'hémorragies gastriques répétées. Un homme politique célèbre ne doit pas mourir, car le médecin qui le traite est sous les feux de la rampe. L'ancien premier ministre israélien Ariel Sharon se trouve depuis sept ans dans un coma profond.

Les médecins personnels qui entreprennent de relater eux-mêmes leur carrière donnent souvent comme personne un tableau intime de celui qu'ils ont servi. Nous citerons ici deux ouvrages en particulier. Dans sa biographie [2] publiée en 2004, l'artiste et chirurgien plasticien irakien Ala Bashir parle de son activité de médecin qu'il a exercée pendant 15 ans dans la famille de Saddam Hussein. Un autre récit intéressant est celui de Li Zhisui [3], le médecin qui a soigné Mao de 1954 à 1976. L'auteur a émigré aux Etats-Unis où il a écrit ses mémoires. Le livre a été contesté en Chine pour son contenu, notamment sa description peu flatteuse de Mao en tant que patient, et y reste interdit jusqu'à ce jour. Li Zhisui a accompagné le dictateur depuis le «Grand bond en avant» ordonné par Mao jusqu'à la révolution culturelle et à la mort du leader Il en est resté un portrait bouleversant de l'un des hommes les plus influents de l'histoire moderne.

Le tourisme médical est un secteur en croissance. Les potentats qui font partie de ce cercle exclusif n'ont que faire des toubibs payés à la commission auxquels recourent les communs des mortels étrangers. Ils ont à leur service des diplomates et du personnel d'ambassade. Pinochet allait à Londres, Chávez à Cuba, Mobutu à Lausanne, Bouteflika à Paris, et Moubarak à Heidelberg avant sa destitution. Après son AVC, le dictateur nord-coréen Kim-Jong Il a été soigné par un neurochirurgien français arrivé par avion. Aucun des médecins locaux ne s'était risqué à donner un avis médical. Sa veuve s'en méfiait à tel point qu'elle a pris secrètement l'avion pour Berlin pour un traitement orthopédique à l'hôpital universitaire. Tous les puissants aiment la discrétion, comme du reste leurs médecins grassement payés. Berlusconi peut sans soucis se faire «lifter» dans son propre pays. D'autres chefs d'Etat ont de bonnes raisons d'éviter leurs médecins et leurs hôpitaux. Ils se rendent en jet privé aux meilleures adresses, accompagnés de leurs médecins personnels. Dans le tourisme médical global, ce sont des clients de luxe à fort pouvoir d'achat, hautement bienvenus et bien protégés. Peu importe ce qu'ils font chez eux.

Erhard Taverna 